\title{
Rabbits as Animal Models in Contemporary Implant Biomaterial Research
}

\author{
${ }^{1}$ Himanshu Arora, ${ }^{2}$ Anil Nafria, ${ }^{3}$ Anup Kanase \\ ${ }^{1}$ Postgraduate Demonstrator, Department of Prosthodontics, Government Dental College, Rohtak, Haryana, India \\ ${ }^{2}$ Senior Resident, Department of Orthodontics and Dentofacial Orthopedics, Maulana Azad Institute of \\ Dental Sciences, New Delhi, India \\ ${ }^{3}$ Associate Professor, Department of Orthodontics and Dentofacial Orthopedics Maulana Azad Institute of \\ Dental Sciences, New Delhi, India
}

\begin{abstract}
Correspondence: Himanshu Arora, House No. 272, Sector-14, Urban Estate, Karnal-132001, Haryana, India, e-mail: drhim_arora@ yahoo.co.in
\end{abstract}

\section{ABSTRACT}

Development of an optimal interface between bone and orthopedic or dental implants has taken place for many years. In order to determine whether a newly developed implant material conforms to the requirements of biocompatibility, mechanical stability and safety, it must undergo rigorous testing both in vitro and in vivo. Results from in vitro studies can be difficult to extrapolate to the in vivo situation. For this reason the use of animal models is often an essential step in the testing of orthopedic and dental implants prior to clinical use in humans. This review discusses the reasons, the importance, and the research carried out in rabbits in our quest to develop a dental implant ideally suited for human bone.

Keywords: Rabbit, Biocompatible, Osseointegration, Dental implant.

\section{INTRODUCTION}

From a general viewpoint, the performances of implanted materials rely on the nature of interaction mechanisms between biomaterials and living cells. ${ }^{1}$ In order to determine whether a new material conforms to the requirements of biocompatibility and mechanical stability prior to clinical use, it must undergo rigorous testing under both initial in vitro and then in vivo conditions. Testing in in vitro conditions is used primarily as a first stage test for acute toxicity and cytocompatibility to avoid the unnecessary use of animals in the testing of cytologically inappropriate materials. However, in vitro characterization is not able to demonstrate the tissue response to materials, instead being confined to the response of individual cell lines or primary cells taken from animals. As in case of dental implants no in vitro cell culture system is able to produce loading that simulates the in vivo situation. Animal models allow the evaluation of materials in loaded or unloaded situations over potentially long time durations and in different tissue qualities (e.g. normal healthy or osteopenic bone) and ages. Not only the tissues in the immediate vicinity of the implant can be assessed but also tissues in remote locations can also be studied, which is particularly relevant to the study of wear particle debris. Currently, there are numerous models for testing implant materials in vivo, ranging in purpose from the assessment of protein adsorption and soft tissue adherence to the integration of bone and the dissemination of implant wear particles.

According to Schimandle and Boden, ${ }^{2}$ animal selection factors include cost to aquire and care for animals, availability, acceptability to society, tolerance to captivity and ease of housing. The rabbit is one of the most commonly used animals for medical research, being used in approximately 35\% of musculoskeletal research studies. ${ }^{3}$ This is in part due to ease of handling and size. The rabbit is also convenient as they reach skeletal maturity shortly after sexual maturity at around 6 months of age. ${ }^{4}$ Guidelines are provided for the dimensions of implants for in vivo studies, based on the size of animal and bone chosen and on the implant design, in order to avoid pathological fracture of the test site. ${ }^{5}$ At least four rabbits and at least two of each of the other species mentioned above should be used for each treatment at each implantation period, though appropriate power calculations should be performed. Long-term implantation periods for these species are given as 12, 26, 52 and 78 weeks. The international standard for the biological evaluation of medical devices recommends a maximum of six implants (3 test and 3 control implants) per rabbit. Cylindrical implants placed into rabbit tibial and femoral diaphyseal bone should be no larger than $2 \mathrm{~mm}$ in diameter and $6 \mathrm{~mm}$ in length (Figs $1 \mathrm{~A}$ and B). It is extremely important that control implants are included in any study design. These implants should be of a material already in clinical use and should allow the outcome data to be related to existing products. ${ }^{5}$ The chosen implant design will determine the experimental techniques used to evaluate the material, in particular the mechanical testing techniques. Common mechanical testing used on tissues harvested from in vivo studies include torque removal tests (screw-type implants), pull-out tests and push-out tests (screw and cylindrical implants). These tests are used to evaluate the strength of the interaction between the bone and implant surface. High forces encountered during these tests indicate a good integration between the bone and implant surface or in the case of porous materials, a high degree of bone ingrowth into the pores of the implant. 


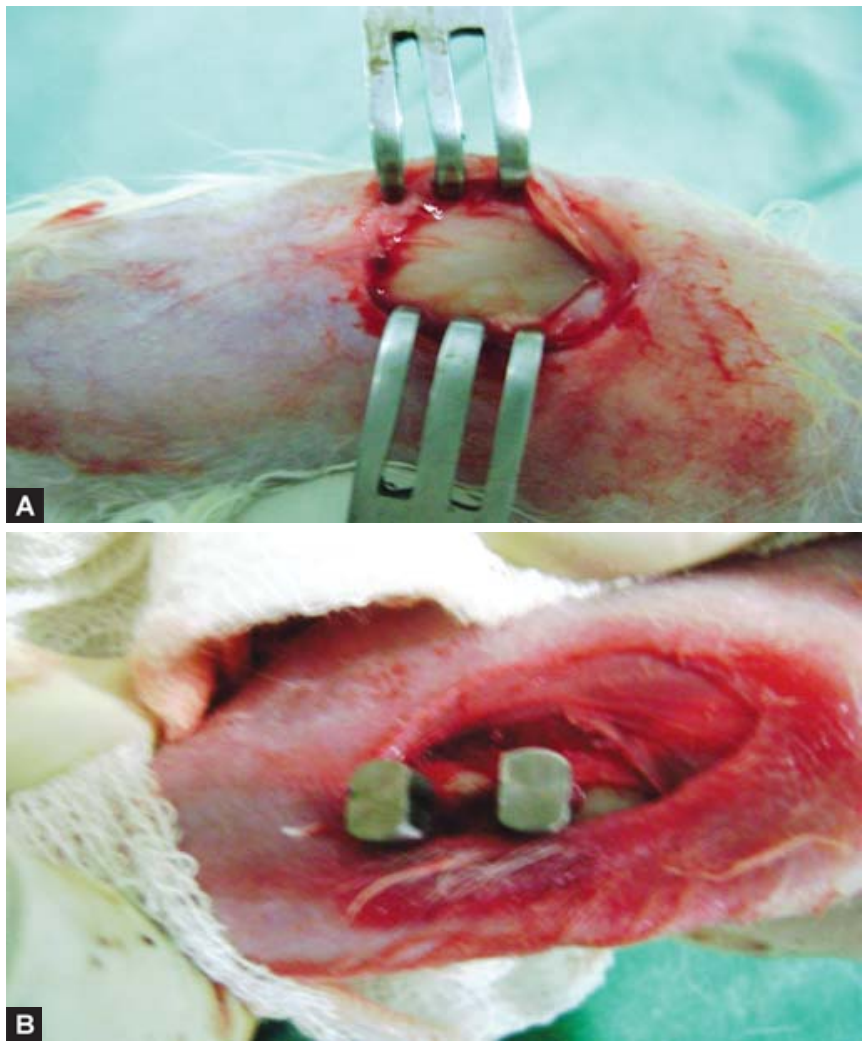

Figs 1A and B: (A) Rabbit tibia before implant placement, (B) implants inserted in rabbit tibia


Figs 2A and B: Polarized light photomicrographs of section through the tibia. (A) Human parallel giant bundles of collagen fibers, (B) thinner collagen fiber bundles in the rabbit

implant loading conditions. Out of these, the first three factors are all implant related and have been investigated by various authors. Rabbits have been used as experimental models in various studies in the quest for determining the most rational implant material, design and surface.

\section{IMPLANT MATERIAL}

Schmidt et al $^{11}$ defined an ideal bone implant material as having a biocompatible chemical composition to avoid adverse tissue reaction, excellent corrosion resistance in the physiologic milieu, acceptable strength, a high resistance to wear and a modulus of elasticity similar to that of bone to minimize bone resorption around the implant. The search for a suitable dental implant that is compatible with hard and soft tissues under functional conditions has led to the utilization of three major materials: Inert metals, plastics and ceramics. Each of these substances has shortcomings when measured against the properties of an ideal implant material. Ivory rod implants were found to be biologically unacceptable in rabbit mandibles. ${ }^{12}$ Fibrous connective tissue capsules containing numerous multinucleated giant cells formed around the implants. Resorption of the ivory was also apparent. In addition, osteoid deposition and ankylosis at the experimental sites were not evident. The possibility of using plastic materials implanted subperiosteally in the mouth to support a dental prosthesis on posts projecting through the mucoperiosteum has been considered. ${ }^{13}$ In another study, adult 
rabbits were used to note the effect of dacron, ivalon, nylon and superpolyamide implants on the surrounding tissues when these materials were placed subperiosteally on the jaws. Nylon, dacron and ivalon elicited continuous inflammatory and foreignbody reactions and did not seem suitable for intraoral implants. Superpolyamide seemed to cause a minimal foreign-body reaction and the most fibrous reaction. It was said that the advantage of this fibrous reaction would be to seal the projecting parts of the implant, minimizing contamination by microorganisms of the mouth. Superpolyamide had many of the features desirable in a substructure of an implant denture. Vitallium and polymethyl methacrylate (PMMA) have been evaluated in an animal model in which bone formation and resorption were independent of each other. ${ }^{14}$ Not material accelerated resorption but formation was inhibited, $12 \%$ by vitallium and $38 \%$ by PMMA. In vivo study of bone ingrowth and bone apposition in porous NiTi has been the subject of much recent literature. The biocompatibility of NiTi and its unusual mechanical properties make it a superior alloy in monolithic, nonporous form for many bone implant applications. These include maxillofacial and dental implants, cervical and lumbar vertebral replacements, joint replacements, bone plates, bone tissue engineering, spine fracture fixation, anchorage and repair. ${ }^{15}$ No apparent adverse reaction was seen on or around the implant area in proximal tibia of rabbit after 6 weeks, and the ingrown bone has similar properties to the surrounding bone. ${ }^{16}$ Shin et al ${ }^{17}$ histomorphometrically compared a noncoated threaded zirconia implant vs a noncoated threaded titanium implant in a rabbit model. They concluded that titanium implants and zirconia implants share a similar degree of bone to implant contact, though titanium implants have a higher amount of bone between the threads as compared to zirconia.

Johansson and Albrektsson ${ }^{18}$ compared screw-shaped titanium and niobium implant in rabbit bone. After a healing period of three months, the removal torque analysis showed a significantly higher removal torque to unscrew niobium implants as compared to titanium implants. On the other hand, histomorphometric analysis failed to find any significant differences in bone-to-implant contact between the two materials. The authors also compared screw-shaped implants made from rods of commercially pure titanium (grade 1) and titanium-aluminum-vanadium (grade 5) in rabbit tibia for healing periods of 1, 6 and 12 months. Quantitative comparisons of the removal torque $(\mathrm{Ncm})$ necessary to loosen the implants from the bone bed were performed. Short-term (1 month) observations revealed no significant differences between the two tested materials. However, after 6 and 12 months, the commercially pure titanium implants were significantly more stable in the bone bed as compared to the alloy samples. Bottino et $\mathrm{al}^{19}$ evaluated the performance of Ti-13Nb-13Zr alloy implants obtained by the hydride route via powder metallurgy in rabbit's tibiae. BSE-SEM evaluation after a healing period of 8 weeks showed close contact between bone and implants. Fluorescent labeling assessment showed high bone activity levels at regions close to the implant surface. Silicon nitride has also been tested as a potential candidate for clinical applications. ${ }^{20}$ After placing SiN implants in rabbit tibiae for 8 weeks and evaluating the newly formed bone around the implants, it was said that $\mathrm{SiN}$ can be used as a biomaterial. Recently, the applicability of fiber reinforced composites (FRC) with porous structure as an implant material has been studied. ${ }^{21}$ After placing in rabbit femur and tibia for a period of 12 weeks these implants showed significantly higher values as compared to PMMA or titanium implants when subjected to push-out tests.

\section{IMPLANT MACRODESIGN}

Caravallo and Junior ${ }^{22}$ analyzed the bone response to smoothas-machined screw shaped implants after placement in rabbit tibia. The stereological analysis showed a great amount of cortical bone in the thread near the cortical bone of the tibia. There was a minor quantity of new bone formation in the medullary cavity. Vasconcellos et $\mathrm{a}^{23}$ studied the bone response to porous and rough implants. The fixation and the bone ingrowth at the interface of porous cylindrical implants (total porosity of $37 \%$ and average pores diameter of $480 \mu \mathrm{m}$ ) were compared in vivo to rough cylindrical implants $(\mathrm{Ra}=5.3 \mu \mathrm{m})$, both of commercially pure titanium, made by powder metallurgy. The implants were inserted into the tibiae of 20 rabbits and the animals were sacrificed 4 and 8 weeks after surgery. The percentage of bone-implant contact observed in porous implant was significantly larger than in the rough ones for all of sacrifice periods. O'Sullivan et $\mathrm{al}^{24}$ studied the influence of implant taper on the stability of osseointegrated titanium implants. The primary and secondary stability characteristics of endosseous titanium implants with $1^{\circ}$ and $2^{\circ}$ of taper were compared with the standard Branemark design. The study showed that $1^{\circ}$ of taper resulted in a better primary stability compared with the standard Branemark design. There was no evidence that the tapered design caused negative bone tissue reactions. Hall et al ${ }^{25}$ studied bone growth in implants having macroscopic grooves. 110 and $200 \mu \mathrm{m}$ wide and $70 \mu \mathrm{m}$ deep grooves were positioned at a thread flank of oxidized titanium implants before placing them into rabbits for a period of 6 weeks. The results showed that 110 and $200 \mu \mathrm{m}$ wide and $70 \mu \mathrm{m}$ deep grooves at oxidized implant surfaces stimulated bone to preferentially form within and along the groove in the rabbit model. The authors suggested that implants with such a groove may be one way to optimize implant stability in suboptimal clinical conditions. Steigenga et $\mathrm{al}^{26}$ evaluated the effects of dental implant thread design on the quality and percent of osseointegration and resistance to reverse torque in the tibia of rabbits. Each tibia received three implants of varying thread shapes: One with a V-shaped, one with a reverse buttress, and one with a square thread design. The rabbits were sacrificed following an uneventful healing period of 12 weeks. The authors found that the square thread design implants had significantly more bone-to-implant contact (BIC) and greater reverse-torque 
measurements compared to the $\mathrm{V}$-shaped and reverse buttress thread designs, while no differences were found in radiographic bone density assessments. They concluded that the square thread design may be more effective for use in endosseous dental implant systems.

\section{IMPLANT MICRODESIGN}

The surface morphology of dental implants has received increasing attention in recent years. ${ }^{27,28}$ Macroscopic characteristics of the implant surface influence cellular events present at the bone biomaterial interface and are critical for the long-term survival of the implant. ${ }^{28}$ The cells have been demonstrated to be sensitive to microtopography. Osteoblasts showed an initial attachment to rough titanium (Ti) surfaces, and further Ti surface roughness has been shown to affect osteoblast proliferation and differentiation. ${ }^{28,29}$ Surface blasting is a process by which metal surfaces are treated with different types of materials (aluminum oxide, titanium oxide, etc.) to provide an irregular surface. ${ }^{30}$ Blasted surfaces show a rough irregular topography with numerous randomly oriented rough features. Surface blasting, in addition to increasing the surface roughness, removes surface contaminants and increases surface reactivity of the metal. ${ }^{31}$ Also, a significantly higher torque was required for the removal of blasted implants. ${ }^{31}$ Gotfredsen et $\mathrm{al}^{30}$ found that more bone came into contact with the implant surface when using titanium dioxide $\left(\mathrm{TiO}_{2}\right)$-blasted implants rather than as-machined, turned ones. The release of ions from the roughened implant surface has also been tested in rabbits. No negative effects from aluminum $(\mathrm{Al})$ ions were seen on the peri-implant bone tissues, even if blasted surfaces contained a significant amount of aluminum, most probably because with blasted implants only a limited and transient release of $\mathrm{Al}$ ions occurs. ${ }^{32}$ Wennerberg et $\mathrm{al}^{33}$ found no correlation between ion release and surface roughness levels of commercial implants.

Rabbit bone has also been used to compare the osseointegrative capabilities between implants modified by anodization and acid etching and machined implants. Dual acidethched implants have demonstrated enhanced bony anchorage in rabbit bone when compared with machined implants. ${ }^{34-37}$ It is thought that a irregular porous surface structure in the nanometer to micron level is favorable to mechanical interlocking between bone tissue and implant surface. Hansson and Norton ${ }^{38}$ pointed out that the optimization of roughened surface parameters on the microscopic scale depended on the size, cross-sectional and opening shape, and density of micropits. They came to a conclusion that among the common shapes studied, half-spherical micropits showed the highest retentive capacity, $1-5 \mu \mathrm{m}$ in diameter being the optimal size with the highest pit affectivity factor. Buser et $\mathrm{al}^{39}$ confirmed that the implants with a sandblasted and acid-etched (SLA) surface yielded a higher mean RTQ than the machined implants. A higher degree of bone-to-implant contact has also been demonstrated when titanium implants with anodized surface are placed in rabbit bone as compared with non-anodized implants. ${ }^{40-42}$ Elias et $\mathrm{al}^{43}$ observed that the implant surface morphology affects titanium biocompatibility and cell function. The surface roughness changes the cells' adhesion force to the surface and modifies the connection between them. The force of the union of the cells to the surface can be modified by the presence of different cells, which are more numerous when fibronectin exists on the surface. The shape of the cells regulates their growth, genetic expression and secretion of proteins. It also modifies differentiation and cellular death. The roughness levels can influence osteoblast and osteoclast formation. Hydroxyapatite- coated and plasma-sprayed implants showed a better bone response when placed in rabbit bone. ${ }^{44-47}$ Bone formation has also been found to be better around laser textured implants in rabbits. ${ }^{48,49}$

\section{SUMMARY}

The development and modification of dental implants has taken place for many years in an effort to create an optimal interaction between the body and the implanted material. The goal of achieving an optimal bone-implant interface has been approached by the alteration of implant surface topography, chemistry, energy and charge, as well as bulk material composition. The features relating to implant safety, such as avoidance of adverse tissue reaction and resistance to wear and corrosion, are of high clinical significance for implants used in long-term clinical situations in both human and veterinary medicine as there have been some links between prolonged exposure to nonbiocompatible materials and neoplastic tissue responses. In order to determine whether a new material conforms to the requirements of biocompatibility and mechanical stability prior to clinical use, it must undergo rigorous testing under both initial in vitro and then in vivo conditions. In vitro testing is popular for the characterization of bone-contacting materials, particularly as medical researchers embrace the principles of animal reduction.

It is accepted that in vitro testing be used primarily as a first stage test for acute toxicity and cytocompatibility to avoid the unnecessary use of animals in the testing of cytologically inappropriate materials. Animal models allow the evaluation of materials in loaded or unloaded situations over potentially long time durations and in different tissue qualities (e.g. normal healthy or osteopenic bone) and ages. Not only the tissues in the immediate vicinity of the implant can be assessed but also tissues in remote locations can also be studied, which is particularly relevant to the study of wear particle debris.

Rabbits are one of the most commonly used animals in contemporary research for the most suitable dental implant. Even though the resemblance between rabbit and human bone is very less, they still are used very commonly due the ease of handling and size and their rapid achievement of sexual maturity. However, differences between healing rates in animal models and humans, variance of bony sites and implant parameters, and variability of biomechanical tests and conditions prevent 
direct correlation of these histomorphometric and biomechanical results to the prediction of clinical results.

\section{REFERENCES}

1. Ramires PA, Giuffrida A, Milella E. Three-dimensional reconstruction of confocal laser microscopy images to study the behaviour of osteoblastic cells grown on biomaterials. Biomaterials Jan 2002;23(2):397-406.

2. Schimandle JH, Boden SD. Spine update: The use of animal models to study spinal fusion. Spine (Phila Pa 1976) 1 Sep 1994;19(17):1998-2006.

3. Neyt JG, Buckwalter JA, Carroll NC. Use of animal models in musculoskeletal research. Iowa Orthop J 1998;18:118-23.

4. Gilsanz V, Roe TF, Gibbens DT, Schulz EE, Carlson ME, Gonzalez O, Boechat MI. Effect of sex steroids on peak bone density of growing rabbits. Am J Physiol Oct 1988;255(4 Pt 1):E416-21.

5. International Standard ISO 10993-6. Biological evaluation of medical devices. 1994(Pt 6):1-11.

6. Wang X, Mabrey JD, Agrawal CM. An interspecies comparison of bone fracture properties. Biomed Mater Eng 1998;8(1):1-9.

7. Martiniaková M, Omelka R, Chrenek P, Ryban L, Parkányi V, Grosskopf B, Vondráková M, Bauerová M. Changes of femoral bone tissue microstructure in transgenic rabbits. Folia Biol (Praha) 2005;51(5):140-44.

8. Kääb MJ, Gwynn IA, Nötzli HP. Collagen fibre arrangement in the tibial plateau articular cartilage of man and other mammalian species. J Anat Jul 1998;193(Pt 1):23-34.

9. Castañeda S, Largo R, Calvo E, Rodríguez-Salvanés F, Marcos ME, Díaz-Curiel M, Herrero-Beaumont G. Bone mineral measurements of subchondral and trabecular bone in healthy and osteoporotic rabbits. Skeletal Radiol Jan 2006;35(1): 34-41.

10. Albrektsson T, Brånemark PI, Hansson HA, Lindstrom J. Osseointegrated titanium implants. Acta Orthop Scand 1981;52:155-70.

11. Schmidt C, Ignatius AA, Claes LE. Proliferation and differentiation parameters of human osteoblasts on titanium and steel surfaces. J Biomed Mater Res Feb 2001;54(2):209-15.

12. Ceravolo FJ, Molinari JA, Baumhammers A. Histological response to ivory implanted in rabbit mandibles. J Dent Res 1975;54:561-66.

13. Boucher L, Surwillo E. The effect of plastic implants on jaws and adjacent tissues of the rabbit. J Prosth Dent 1968;19: 514-22.

14. Gracia D, Sullivan T, O'neill D. The biocompatibility of dental implant materials measured in an animal model. J Dent Res 1981;60:44-49.

15. Shabalovskaya SA. On the nature of the biocompatibility and on medical applications of NiTi shape memory and superelastic alloys. Bio-Med Mater Eng 1996;6:267-89.

16. Kim JS, Kang JH, Kang SB, Yoon KS, Kwon YS. Porous TiNi biomaterial by self-propagating high-temperature synthesis. Adv Eng Mater 2004;6:403-06.

17. Shin D, Ito M, Chu T. Preliminary histomorphometric comparisons of two implant biomaterials in a rabbit model. Dental Materials 2010;26(2):e152.

18. Johansson CB, Albrektsson T. A removal torque and histomorphometric study of commercially pure niobium and titanium implants in rabbit bone. Clin Oral Impl Res 1991;2: 24-29.
19. Bottino M, Coelho P, Yoshimoto M. Histomorphologic evaluation of $\mathrm{Ti}-13 \mathrm{Nb}-13 \mathrm{Zr}$ alloys processed via powder metallurgy. A study in rabbits. Materials Science and Engineering C 2008;28:223-27.

20. Guedes e Silva C, König Jr B, Carbonari M, Yoshimoto M, Allegrini S, Bressiani J. Bone growth around silicon nitride implants-An evaluation by scanning electron microscopy. Material Characterization 2008;59:1339-41.

21. Mattila R, Laurila P, Rekola J, Gunn J, Lassila L. Bone attachment to glass-fibre-reinforced composite implant with porous surface. Acta Biomaterialia 2009;5:1639-46.

22. Carvalho Lopes C, König Jr B. Histological findings of bone remodeling around smooth dental titanium implants inserted in rabbit's tibias. Ann Anat 2002;184:359-62.

23. Vasconcellos L, Oliviera M, Graca M, Vasconcellos L. Design of dental implants, influence on the osteogenesis and fixation. $\mathrm{J}$ Mater Sci: Mater Med 2008;19:2851-57

24. O'Sullivan D, Sennerby L, Meredith N. Influence of implant taper on the primary and secondary stability of osseointegrated titanium implants. Clin Oral Implants Res Aug 2004;15(4): 474-80.

25. Hall J, Miranda-Burgos P, Sennerby L. Stimulation of directed bone growth at oxidized titanium implants by macroscopic grooves: An in vivo study. Clin Implant Dent Relat Res 2005;7Suppl 1:S76-82.

26. Steigenga J, Al-Shammari K, Misch C, Nociti FH Jr, Wang HL. Effects of implant thread geometry on percentage of osseointegration and resistance to reverse torque in the tibia of rabbits. J Periodontol Sep 2004;75(9):1233-41.

27. Cochran DL, Nummokoski PV, Higginbottom FL, Hermann JS, Makins SR, Buser D. Evaluation of an endosseous titanium implant with a sandblasted and acid-etched surface in the canine mandible: Radiographic results. Clin Oral Implants Res 1996; 7:240-52.

28. Bowers KT, Keller J, Randolph BA, Wick DG, Michaels CM. Optimization of surface micromorphology for enhanced osteoblast responses in vitro. Int J Oral Maxillofac Implants 1992; 7:302-10.

29. Schwartz Z, Martin JY, Dean DD, Simpson J, Cochran DL, Boyan BD. Effect of titanium surface roughness on chondrocyte proliferation, matrix production, and differentiation depends on the state of cell maturation. J Biomed Mater Res1996;30: 145-55.

30. Gotfredsen K, Wennerberg A, Johansson C, Skovgaard LT, Hjørting-Hansen E. Anchorage of $\mathrm{TiO}_{2}$-blasted, HA-coated and machined implants: An experimental study with rabbits. J Biomed Mater Res 1995;29:1223-31.

31. Wennerberg A, Albrektsson T, Johansson C, Andersson B. Experimental study of turned and grit-blasted screw-shaped implants with special emphasis on effects of blasting material and surface topography. Biomaterials 1996;17:15-22.

32. Wennerberg A, Albrektsson T, Lausmaa J. Torque and histomorphometric evaluation of c.p. titanium screws blasted with 25- and 75- $\mu \mathrm{m}$-sized particles of $\mathrm{Al}_{2} \mathrm{O}_{3}$. J Biomed Mater Res 1996;30:251-60.

33. Wennerberg A, Ide-Ektessabi A, Hatkamata S, Sawase T, Johansson C, Albrektsson T, Martinelli A, So“dervall U, Odelius H. Titanium release from implants prepared with different surface roughness: An in vitro and in vivo study. Clin Oral Impl Res 15:2004;505-12.

34. Klokkevold PR, Johnson P, Dadgostari S, Caputo A, Davies JE, Nishimura RD. Early endosseous integration enhanced by dual acid etching of titanium: A torque removal study in the rabbit. Clin Oral Impl Res 2001;12:350-57. 
35. Cordioli G, Majzoub Z, Piattelli A, Scarano A. Removal torque and histomorphometric investigation of 4 different titanium surfaces: An experimental study in the rabbit tibia. Int J Oral Maxillofac Implants 2000;15:668-74.

36. Cho SA, Park KT. The removal torque of titanium screw inserted in rabbit tibia treated by dual acid etching. Biomaterials Sep 2003;24(20):3611-17.

37. Klokkevold PR, Nishimura RD, Adachi M, Caputo A. Osseointegration enhanced by chemical etching of the titanium surface: A torque removal study in the rabbit. Clin Oral Implants Res Dec 1997;8(6):442-47.

38. Hansson $\mathrm{S}$, Norton M. The relation between surface roughness and interfacial shear strength for bone-anchored implants. A mathematical model. J Biomech 1999;32:829-36.

39. Buser D, Nydegger T, Oxland T, Cochran DL, Schenk RK, Hirt $\mathrm{HP}$, et al. Interface shear strength of titanium implants with a sandblasted and acid-etched surface: A biomechanical study in the maxilla of miniature pigs. J Biomed Mater Res 1999;45: 75-83.

40. Larsson C, Thomsen P, Aronsson BO, Rodahl M, Lausmaa J, Kasemo B, Ericson LE. Bone response to surface-modified titanium implants: Studies on the early tissue response to machined and electropolished implants with different oxide thicknesses. Biomaterials Mar 1996;17(6):605-16.

41. Yamagami A, Yoshihara Y, Suwa F. Mechanical and histologic examination of titanium alloy material treated by sandblasting and anodic oxidization. Int $\mathrm{J}$ Oral Maxillofac Implants 2005;20:48-53.
42. Sul YT, Johansson CB, Röser K, Albrektsson T. Qualitative and quantitative observations of bone tissue reactions to anodised implants. Biomaterials Apr 2002;23(8):1809-17.

43. Elias CN, Oshida Y, Lima JH, Muller CA. Relationship between surface properties (roughness, wettability and morphology) of titanium and dental implant removal torque. J Mech Behav Biomed Mater Jul 2008;1(3):234-42.

44. Hayakawa T, Yoshinari M, Kiba H, Yamamoto H, Nemoto K, Jansen JA. Trabecular bone response to surface roughened and calcium phosphate (Ca-P) coated titanium implants. Biomaterials Feb 2002;23(4):1025-31.

45. Mitri FF, Yoshimoto M, Allegrini Júnior S, Koo S, Carbonari MJ, König Júnior B. Histological findings in titanium implants coated with calcium phosphate ceramics installed in rabbit's tibias. Ann Anat Mar 2005;187(1):93-98.

46. O'Hare P, Meenan BJ, Burke GA, Byrne G, Dowling D, Hunt JA. Biological responses to hydroxy apatite surfaces deposited via a coincident microblasting technique. Biomaterials Jan 2010;31(3):515-22.

47. Gotfredsen K, Berglundh T, Lindhe J. Anchorage of titanium implants with different surface characteristics: An experimental study in rabbits. Clin Implant Dent Relat Res 2000;2(3): $120-28$.

48. Hallgren C, Reimers H, Chakarov D, Gold J, Wennerberg A. An in vivo study of bone response to implants topographically modified by laser micromachining. Biomaterials Feb 2003;24(5):701-10.

49. Cho SA, Jung SK. A removal torque of the laser-treated titanium implants in rabbit tibia. Biomaterials Nov 2003;24(26): 4859-63. 